\title{
Effect of sodium bicarbonate on Candida albicans adherence to thermally activated acrylic resin
}

\section{Fernando Augusto Cervantes Garcia de Sousa ${ }^{(a)}$ \\ Thaís Cachuté Paradella(a) Cristiane Yumi Koga-Ito(b) Antonio Olavo Cardoso Jorge(b)}

(a) Doctorate Student; (b) Professor of Microbiology - Department of Bioscience and Oral Diagnosis, School of Dentistry of São José dos Campos, São Paulo State University, São José dos Campos, SP, Brazil.

\begin{abstract}
The purpose of this study was to evaluate the effect of $5 \%$ sodium bicarbonate on the adherence of Candida albicans to thermally activated acrylic resin. Fifty $4 \mathrm{~mm}^{2}$ specimens of acrylic resin were obtained using a metallic matrix. The specimens received chemical polishing, were sterilized and then immersed in Sabouraud broth, inoculated with Candida albicans standardized suspension. After 24 hours of incubation at $37^{\circ} \mathrm{C}$, the specimens were divided into four groups according to the substance used for disinfection $(5 \%$ sodium bicarbonate, $0.12 \%$ digluconate chlorhexidine, vinegar and Corega Tabs). A control group was included, in which distilled water was used. The adhered microorganisms were dispersed, diluted and plated onto culture media to determine the number of colony-forming units $(\mathrm{cfu} / \mathrm{mL})$. The results were analyzed through the Mann-Whitney statistical test at the 5\% level of significance. Only $0.12 \%$ digluconate chlorhexidine and $5 \%$ sodium bicarbonate presented a statistically significant difference $(\mathrm{p}=0.0010$ and $\mathrm{p}=0.0156$, respectively) compared to the control group, decreasing the number of $\mathrm{cfu} / \mathrm{mL}$. However, when the different disinfecting solutions were compared with each other, only $0.12 \%$ digluconate chlorhexidine presented a statistically significant difference in the reduction of $\mathrm{cfu} / \mathrm{mL}$. It was concluded that although $0.12 \%$ digluconate chlorhexidine was more effective in the reduction of Candida albicans adherence values to thermally activated acrylic resin, 5\% sodium bicarbonate also proved to be a viable alternative.
\end{abstract}

Descriptors: Sodium bicarbonate; Acrylic resins; Candida albicans; Cell adhesion.

\section{Corresponding author:}

Fernando Augusto Cervantes Garcia de Sousa

R. Irmã Maria Demétria Kfuri, 196

São José dos Campos - SP - Brazil CEP: 12242-500

E-mail: facgs@uol.com.br

Received for publication on May 23, 2008 Accepted for publication on Oct 30, 2008 


\section{Introduction}

In spite of all advances in dentistry, complete dentures are still essential for oral rehabilitation of edentulous dental arches. However, this type of prosthesis, which is basically confectioned with thermally activated acrylic resin, constitutes a favorable environment for the colonization and proliferation of Candida genus yeasts, since these microorganisms have the ability to strongly adhere to polymethylmethacrylate, which constitutes the acrylic resin. ${ }^{1,2}$

This phenomenon, in association with factors such as trauma, diet, poor hygiene or predisposing systemic conditions (xerostomia, hormonal alterations and immunodepression caused by diabetes mellitus or HIV infection), may lead complete denture users to develop a condition known as denture stomatitis. ${ }^{3-7}$ This condition is clinically characterized by a discrete focal inflammation on the palatum, which can evolve to an intense erythema in all area covered by the denture and, in some cases, to papillary hyperplasia. ${ }^{6}$

According to Daniluk et al..$^{5}$ (2006), Candida genus yeasts can be isolated from the human oral cavity in $64.9 \%$ of patients with denture stomatitis, being Candida albicans the most prevalent species $(78.4 \%)$. In fact, studies have shown that regardless of the presence of clinical symptoms, Candida albicans is more prevalent in complete denture users than in the general population. ${ }^{2,5,8}$ This condition makes complete denture users more susceptible to the development of other forms of candidosis when submitted to conditions that might lead to a disequilibrium in the oral microbiota, such as usage of broad-spectrum antibiotics, anti-histamines, chemo- or radiotherapy. The presence of conditions that cause reduction in salivary flow, including diabetes mellitus, drug usage, poor nutrition and advanced age, for instance, may also cause oral microbiota disequilibrium..$^{9-12}$

However, simple attitudes such as the removal of the denture during the night and its correct hygiene with the daily usage of disinfecting solutions are mentioned in the literature as effective in the prevention and treatment of denture stomatitis., ${ }^{43-15}$ Thus, many studies have been performed with the objec- tive of evaluating the efficiency of different disinfecting solutions in the control of Candida genus yeasts, searching for a disinfecting solution that would present excellent antimicrobial activity without harming the patient's health or causing alterations in the physical-structural characteristics of dentures. ${ }^{16-20}$

Within this context, the objective of the present study was to evaluate the effect of sodium bicarbonate in the adherence of Candida albicans to thermally activated acrylic resin, comparing it to other disinfecting solutions already mentioned and tested in the literature.

\section{Material and Methods}

Fifty $4 \mathrm{~mm}^{2}$ standardized specimens were obtained using thermally activated acrylic resin (Artigos Odontológicos Clássico Ltda., São Paulo, SP, Brazil) and an aluminum matrix. Chemical polishing of the specimens was performed using a Termotron PQ9000 chemical polisher (Termotron do Brasil Ltda., Piracicaba, SP, Brazil). The specimens were kept in glass recipients containing physiological serum $(0.85 \% \mathrm{NaCl})$, sterilized in autoclave $\left(121^{\circ} \mathrm{C} / 15 \mathrm{~min}\right)$ and submitted to adherence testing. ${ }^{21}$

Candida albicans ATCC 1880 was plated on Sabouraud's dextrose agar and incubated at $37^{\circ} \mathrm{C}$ for 24 hours. After this period, a suspension containing $10^{6}$ viable cells per milliliter was prepared in sterile saline solution $(0.85 \% \mathrm{NaCl})$ with the aid of a UV-1203 Shimadzu spectrophotometer (Shimadzu Corp., Kyoto, Japan), adopting the wavelength of $530 \mathrm{~nm}$ and optical density of 0.284 .

Adherence testing was performed in an aseptic environment, in a laminar air flow chamber using 24-wells plates for cell culture. For this purpose, $1.5 \mathrm{~mL}$ of Sabouraud broth (Difco Labs., Detroit, MI, USA), one specimen and $0.1 \mathrm{~mL}$ of Candida albicans standardized suspension were added to each well. The plates were sealed and incubated at $37^{\circ} \mathrm{C}$ for 24 hours.

After this period of incubation, the specimens were washed with $1 \mathrm{~mL}$ of sterile distilled water and randomly divided into five groups $(\mathrm{n}=10)$, according to the disinfecting solution tested: control group (distilled water); group B (5\% sodium bicarbonate - Labsynth Produtos para Laboratórios Ltda., Di- 
adema, SP, Brazil); group V (white vinegar - Castelo Alimentos, Jundiaí, SP, Brazil); group C (Corega Tabs - GlaxoSmithKline Brasil Ltda., Rio de Janeiro, RJ, Brazil); and group $\mathrm{P}(0.12 \%$ digluconate chlorhexidine - Periogard - Colgate Palmolive Ind. e Com. Ltda., São Paulo, SP, Brazil). The specimens were immersed for 10 minutes in $10 \mathrm{~mL}$ of the corresponding solution, according to the group.

After immersion, the specimens were then removed, washed with $1 \mathrm{~mL}$ of sterile distilled water and transferred to tubes containing $1 \mathrm{~mL}$ of sterile physiological solution $(0.85 \% \mathrm{NaCl})$ and glass pearls. The tubes were agitated in a Vortex stirrer for 60 seconds and the adhered cells were dispersed. This initial suspension was diluted 10, 100 and 1,000 times in physiological solution, and $0.1 \mathrm{~mL}$ of each suspension was plated in duplicate on $\mathrm{Sa}$ bouraud dextrose agar (Difco Labs., Detroit, MI, USA). After 48 hours of incubation at $37^{\circ} \mathrm{C}$, the number of colony-forming units per specimen (cfu/ specimen) was determined.

The data was statistically analyzed through the Mann-Whitney test, at the 5\% level of significance, comparing groups two by two.

\section{Results}

The mean value of $\mathrm{cfu} / \mathrm{mL} \pm$ standard deviation in the control group was $7.50 \times 10^{3}\left( \pm 5.69 \times 10^{3}\right)$. Meanwhile, groups B, V, C and P presented, respectively, the following results: $2.55 \times 10^{3}$ $\left( \pm 1.80 \times 10^{3}\right) ; 6.04 \times 10^{3}\left( \pm 7.96 \times 10^{3}\right) ; 6.01 \times 10^{3}$ $\left( \pm 6.55 \times 10^{3}\right) ; 1.05 \times 10^{3}\left( \pm 1.58 \times 10^{3}\right)$. Group P presented the highest reduction in comparison to the control group $(86.00 \%)$, followed by groups B (66.00\%), C (19.90\%) and V (19.50\%). (Graph 1)

In fact, only groups $\mathrm{P}$ and $\mathrm{B}$ showed significant statistical difference when compared to the control group $(\mathrm{p}=0.0010$ and $\mathrm{p}=0.0156$, respectively). However, when the experimental groups were compared with each other, only group $\mathrm{P}$ presented significant statistical difference $(\mathrm{P} \times \mathrm{B}, \mathrm{p}=0.0211$; $\mathrm{P} \times \mathrm{V}, \mathrm{p}=0.0233 ; \mathrm{P} \times \mathrm{C}, \mathrm{p}=0.0046)$.

\section{Discussion}

Chlorhexidine's efficiency in the treatment of denture stomatitis is recognized since $1970 .{ }^{22}$ Budtz-
Jörgensen and Löe, ${ }^{23}$ in 1972, showed that disinfection of complete dentures with $2 \%$ chlorhexidine for 15 minutes, twice a day, was capable of reducing the inflammation caused by stomatitis and also completely eliminated the presence of Candida hyphae. Lal et al. ${ }^{24}$ (1992) demonstrated similar results after the use of $0.12 \%$ chlorhexidine-based rinsing solutions.

Several studies have shown that the disinfection of complete dentures with either $2 \%$ or $4 \%$ chlorhexidine, as well as the use of either $0.12 \%$ or $0.2 \%$ chlorhexidine-based rinsing solutions is effective in the reduction of the total number of $\mathrm{cfu} / \mathrm{mL}$ of Candida albicans adhered to the surface of acrylic resin and, consequently, effective in the prevention and treatment of denture stomatitis, especially when both methods are associated. ${ }^{18,19,23,24}$ In fact, the results presented in the present study corroborated the findings in the literature, since, among the disinfecting solutions, $0.12 \%$ digluconate chlorhexidine presented the best results, reducing in $86 \%$ the number of microorganisms adhered to the surface of the specimens.

However, although chlorhexidine presents excellent antimicrobial properties such as low-concentration efficiency, substantivity, minimal perception by the gastrointestinal tract, capacity to reduce biofilm formation and disorganize pre-formed biofilm, ${ }^{22,25}$ ${ }^{27}$ it also presents some side effects, including mild discomfort or burning sensation when chlorhexidine comes in contact with the oral mucosa, in addition to epithelium exfoliation, teeth staining, enhance-

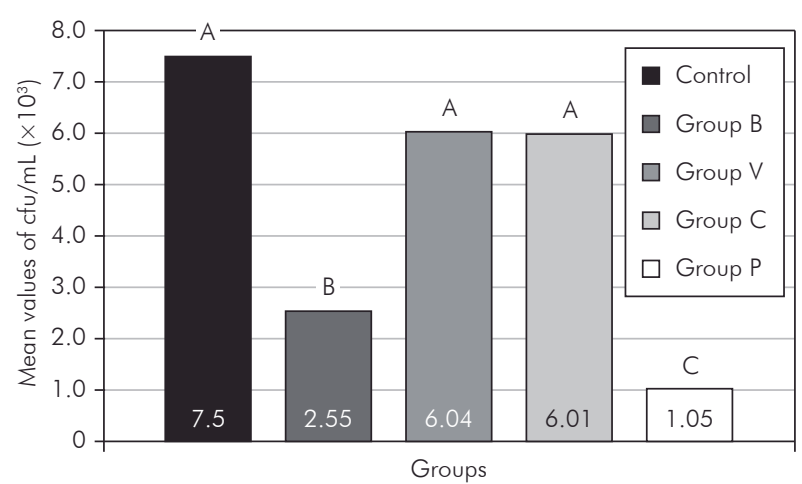

Graph 1 - Mean values of cfu/mL $\left(\times 10^{3}\right)$ of Candida albicans per group (Different letters indicate significant statistical differences). 
ment of supragingival calculus and color alteration of artificial teeth and denture basis. ${ }^{22,23,25,28}$

Thus, there is a need to research alternative disinfecting solutions, aiming at minimizing the side effects of disinfecting solutions to the physical-chemical properties of dentures and to the patient's health. Sodium bicarbonate has been used for disinfection of dentures and orthodontic appliances, but there is no corroboration in the literature to the efficiency of this substance regarding its influence on adherence. Thus, one of the study groups of the present study included sodium bicarbonate, and, based on the results, it has been shown to be a viable alternative, at least considering its anti-Candida adherence effect, since it significantly reduced the adherence of Candida albicans to the surface of the specimens.

In fact, many studies have shown that sodium bicarbonate at high concentrations has an antimicrobial effect over several microorganisms isolated from the oral cavity, including Candida albicans. ${ }^{29,30}$ However, none of these studies evaluated the effect of sodium bicarbonate on the adherence of these microorganisms. According to Newbrun ${ }^{29}$ (1997), sodium bicarbonate presents low abrasion, low cost, relative safety if accidentally ingested and compatibility with the fluoride present in most

\section{References}

1. McCullough MJ, Ross BC, Reade PC. Candida albicans: a review of its history, taxonomy, epidemiology, virulence attributes, and methods of strain differenciation. Int J Oral Maxillofac Surg. 1996 Apr;25(2):136-44.

2. Webb BC, Thomas CJ, Willcox MD, Harty DW, Knox KW. Candida-associated denture stomatitis. Aetiology and management: a review. Part 1. Factors influencing distribution of Candida species in the oral cavity. Aust Dent J. 1998 Feb;43(1):45-50.

3. Arendorf TM, Walker DM. Denture stomatitis: a review. J Oral Rehabil. 1987 May;14(3):217-27.

4. Barbeau J, Séguin J, Goulet JP, de Koninck L, Avon SL, Lalonde B et al. Reassessing the presence of Candida albicans in denture-related stomatitis. Oral Surg Oral Med Oral Pathol Oral Radiol Endod. 2003 Jan;95(1):51-9.

5. Daniluk T, Tokajuk G, Stokowska W, Fiedoruk K, Sciepuk M, Zaremba ML et al. Occurrence rate of oral Candida albicans in denture wearer patients. Adv Med Sci. 2006;51(1):77-80. dentifrices, which is an important advantage over chlorhexidine. This compatibility associated to its efficiency against Streptococcus mutans ${ }^{30}$ makes sodium bicarbonate an excellent option for complete or partial denture users, who still present remaining teeth in the arches.

Regarding white vinegar and Corega Tabs, both were inefficient in the reduction of the number of Candida albicans colonies adhered to the specimens under the conditions in the present study. In addition, the lack of studies regarding these solutions in the literature contraindicates their use, especially by patients who have already presented signs of stomatitis and, therefore, need a more aggressive approach. However, new studies should be performed, using other concentrations and other immersion times, before a definitive conclusion can be reached.

\section{Conclusion}

Based on the results obtained in the present study, it was concluded that, among the disinfecting solutions tested, $0.12 \%$ digluconate chlorhexidine was the most effective in the reduction of Candida albicans adherence to thermally activated acrylic resin. However, $5 \%$ sodium bicarbonate also proved to be a viable alternative.

6. Golecka M, Ołdakowska-Jedynak U, Mierzwinska-Nastalska E, Adamczyk-Sosinska E. Candida-associated denture stomatitis in patients after immunosuppression therapy. Transplant Proc. 2006 Jan;38(1):155-6.

7. Webb BC, Thomas CJ, Willcox MD, Harty DW, Knox KW. Candida-associated denture stomatitis. Aetiology and management: a review. Part 2. Oral diseases caused by Candida species. Aust Dent J. 1998 Jun;43(3):160-6.

8. Kulak Y, Arikan A, Kazazoglu E. Existence of Candida albicans and microorganisms in denture stomatitis patients. J Oral Rehabil. 1997 Oct;24(10):788-90.

9. Budtz-Jorgensen E, Mojon P, Banon-Clément JM, Baehni P. Oral candidosis in long-term hospital care: comparison of edentulous and dentate subjects. Oral Dis. 1996 Dec;2(4):28590.

10. Budtz-Jorgensen E, Mojon P, Rentsch A, Deslauriers N. Effects of an oral health program on the occurrence of oral candidosis in a long-term care facility. Community Dent Oral Epidemiol. 2000 Apr;28(2):141-9. 
11. Heimdahl A, Nord CE. Oral yeast infections in immunocompromised and seriously diseased patients. Acta Odontol Scand. 1990 Feb;48(1):77-84.

12. Southerland JH, Taylor GW, Moss K, Beck JD, Offenbacher S. Commonality in chronic inflammatory diseases: periodontitis, diabetes, and coronary artery disease. Periodontol 2000. 2006;40:130-43.

13. Harrison Z, Johnson A, Douglas CW. An in vitro study into the effect of a limited range of denture cleaners on surface roughness and removal of Candida albicans from conventional heat-cured acrylic resin denture base material. J Oral Rehabil. 2004 May;31(5):460-7.

14. Kanli A, Demirel F, Sezgin Y. Oral candidosis, denture cleanliness and hygiene habits in an elderly population. Aging Clin Exp Res. 2005 Dec;17(6):502-7.

15. Kulak-Ozkan Y, Kazazoglu E, Arikan A. Oral hygiene habits, denture cleanliness, presence of yeasts and stomatitis in elderly people. J Oral Rehabil. 2002 Mar;29(3):300-4.

16. Azevedo A, Machado AL, Vergani CE, Giampaolo ET, Pavarina AC, Magnani R. Effect of disinfectants on the hardness and roughness of reline acrylic resins. J Prosthodont. $2006 \mathrm{Jul} ; 15(4): 235-42$.

17. Barnabé W, de Mendonça Neto T, Pimenta FC, Pegoraro LF, Scolaro JM. Efficacy of sodium hypochlorite and coconut soap used as disinfecting agents in the reduction of denture stomatitis, Streptococcus mutans and Candida albicans. J Oral Rehabil. 2004 May;31(5):453-9.

18. Kulak Y, Arikan A, Delibalta N. Comparison of three different treatment methods for generalized denture stomatitis. J Prosthet Dent. 1994 Sep;72(3):283-8.

19. Pavarina AC, Pizzolitto AC, Machado AL, Vergani CE, Giampaolo ET. An infection control protocol: effectiveness of immersion solutions to reduce the microbial growth on dental prostheses. J Oral Rehabil. 2003 May;30(5):532-6.

20. Pavarina AC, Machado AL, Giampaolo ET, Vergani CE. Effects of chemical disinfectants on the transverse strength of denture base acrylic resins. J Oral Rehabil. 2003 Nov;30(11):1085-9.
21. Oliveira JR, Paradella TC, Rego MA, Koga-Ito CY, Jorge AOC. Evaluation of microbial adherence and superficial roughness of chemically activated acrylic resin after cycling with different disinfectant solutions. Braz Dental Sci. 2007 Apr/Jun;10(2):54-60.

22. Ellepola AN, Samaranayake LP. Adjunctive use of chlorhexidine in oral candidoses: a review. Oral Dis. 2001 Jan;7(1):11 7.

23. Budtz-Jörgensen E, Löe H. Chlorhexidine as a denture disinfectant in the treatment of denture stomatitis. Scand J Dent Res. 1972;80(6):457-64.

24. Lal K, Santarpia RP $3{ }^{\text {rd }}$, Pollock JJ, Renner RP. Assessment of antimicrobial treatment of denture stomatitis using an in vivo replica model system: therapeutic efficacy of an oral rinse. J Prosthet Dent. 1992 Jan;67(1):72-7.

25. Epstein JB. Antifungal therapy in oropharyngeal mycotic infections. Oral Surg Oral Med Oral Pathol. 1990 Jan;69(1):3241.

26. Ferretti GA, Brown AT, Raybould TP, Lillich TT. Oral antimicrobial agents - chlorhexidine. NCI Monogr. 1990;(9):51-5.

27. Ferretti GA, Raybould TP, Brown AT, Macdonald JS, Greenwood M, Maruyama Y et al. Chlorhexidine prophylaxis for chemotherapy- and radiotherapy-induced stomatitis: a randomized double-blind trial. Oral Surg Oral Med Oral Pathol. 1990 Mar;69(3):331-8.

28. Addy M, Moran J, Davies RM, Beak A, Lewis A. The effect of single morning and evening rinses of chlorhexidine on the development of tooth staining and plaque accumulation. A blind cross-over trial. J Clin Periodontol. 1982 Mar;9(2):13440.

29. Newbrun E. The use of sodium bicarbonate in oral hygiene products and practice. Compend Contin Educ Dent Suppl. 1997;18(21):2-7.

30. Silhacek KJ, Taake KR. Sodium bicarbonate and hydrogen peroxide: the effect on the growth of Streptococcus mutans. J Dent Hyg. 2005 Oct;79(4):7. 